\title{
Development and Validation of HPLC assay of Lycopene in Different Matrices
}

\author{
Muhammad Amjad*, Shabbir Hussain, Abdul Rehman Khan \\ Department of Chemistry, Lahore Garrison University, Lahore, Pakistan \\ Email address: \\ amjadqcm@gmail.com (M. Amjad),dr.shabbirhussain@lgu.edu.pk (S. Hussain), Abdulrehmankhan878@gmail.com (A. R. Khan) \\ ${ }^{*}$ Corresponding author
}

\section{To cite this article:}

Muhammad Amjad, Shabbir Hussain, Abdul Rehman Khan. Development and Validation of HPLC assay of Lycopene in Different Matrices. Science Journal of Chemistry. Vol. 5, No. 2, 2020, pp. 26-33. doi: 10.11648/j.wjac.20200502.13

Received: May 11, 2020; Accepted: May 29, 2020; Published: July 13, 2020

\begin{abstract}
Lycopene is the red pigment richly found in many red -colored fruits and vegetables such as tomatoes, papaya, pink grapefruit, pink guava, and watermelon. It is an antioxidant that has various beneficent effects and protects against oxidative damage to lipids, protein, and DNA. It is a potent quencher of oxygen and most effective against cancer, cardiovascular diseases, osteoporosis, hypertension, male infertility, and neurodegenerative disease. Lycopene is synthesized by plants and microorganisms but not animals and humans. The main objective of this study is to develop and validate an HPLC assay method for the determination of lycopene in tomato, watermelon, and human blood. A simple assay method is an economical assay method, suitable for the determination of lycopene from plant and biological sources. A new accurate, specific, precise, high performance liquid chromatographic (HPLC) method has been developed and validated for the determination of lycopene in tomatoes, watermelon and blood sample according to the International Conference on Harmonization ( $\mathrm{ICH})$ guidelines. Acetonitrile, Methanol, Water $(65 \%, 20 \%$, and $15 \%)$ was used as the mobile phase at a flow rate of $0.7 \mathrm{ml} / \mathrm{min}$. using a symmetry $\mathrm{C} 18$ column. The effluent was spectrophotometrically monitored at $484 \mathrm{~nm}$. The calibration curve was linear with a correlation coefficient of 0.9994 . The average recovery was found to be $102.0 \%$. The proposed HPLC method was successfully applied to quantify the amount of lycopene in different matrices.
\end{abstract}

Keywords: HPLC, Lycopene, C18, Correlation Coefficient, Validation

\section{Introduction of Lycopene}

\subsection{Historical Background}

The name of lycopene is derived from the neo-Latin Lycopersicum, the tomato's species classification, Solanum Lycopersicum. Lycopene is the most powerful carotenoid quencher of singlet oxygen. The main source of natural antioxidants is fruits and vegetables. The body is sheltered from the detrimental effects of free radicals by using antioxidants. The body is also protected against cancer and heart diseases. Among antioxidants, lycopene is one of the most efficient antioxidant's carotenoids. The body is protected from the negative effects of oxidants by using natural pigment lycopene. Lycopene neutralizes the harmful effects of oxidants.

There is a big role of lycopene as an intermediate in the synthesis of vitamin A. carotenoid such as $\beta$-carotene and $\beta$ - cryptoxent influences the development of vitamin A. When we see the solubility of Lycopene then we find that it is soluble in non- polar solvents and insoluble in water. Lycopene is also soluble in fat. Lycopene is synthesized by plants and microorganisms but not by Animals and humans. There is a good effect of regular in taking lycopene containing food because lycopene reduces the risk of body tumor Such as prostate cancer. The study of antioxidants shows that vitamin selenium and lycopene all are very useful to reduce the risk of prostate cancer.

Therefore, it would say that in the prevention of cancer Lycopene is very important. International Guidelines for diet recommended that the increased use of fruits and vegetables which are rich in antioxidants to prevent chronic diseases. In recent research, it is focused that lycopene is a chemopreventive means to treat degenerative diseases. As a major carotenoid in human blood, lycopene protects against oxidative damage to lipids, proteins, and DNA. Lycopene is a potent quencher of singlet oxygen (a reactive form of 
oxygen), which suggests that it may have comparatively stronger antioxidant properties than other major plasma carotenoids.

The lycopene isomers found in human blood plasma, breastmilk, and human tissues are mainly of the cis-isomer type. Lycopene is a non-provitamin A carotenoid present in human blood and tissues. The major dietary sources of lycopene for the human are tomatoes and watermelons. In human blood, various cis-isomers constitute more than $60 \%$ of the total lycopene concentration.

\subsection{Justification}

Creating awareness in any kind of technology requires an understanding model supported intensive promotional works. Obviously, people all over the world have been suffering from dreadful chronic diseases. Cancer is one of the most killer chronic diseases in human history. Once somebody victim with cancer, it is difficult and/or impossible to back his/her previous healthy life again. Based on today's evidence, the foods we eat are likely to play a greater role in preventing cancer than in treating it. The major problem of people living all over the world (especially in Ethiopia) to cause cancer is a lack of awareness. When the people consciousness strengthens on the pros and cons of foods that they feed; the probability of being victimized by cancer will decrease.

\subsection{Scope of the Study}

The scope of this study includes following:

1. Extraction of Lycopene from raw tomato, raw watermelon, and human blood.

2. Spectroscopic analysis to find Absorbance of Lycopene by varying the concentration.

3. Identification of Lycopene by UV-vis spectroscopy,

4. Identification of Lycopene by HPLC method and Development and Validation of an HPLC assay.

5. Evaluation of the content of Lycopene in different samples of tomato, watermelon, and human blood.

\subsection{Objective of the Study}

The major objective of this study is to develop and validate an HPLC assay method for the determination of lycopene in tomato, watermelon, and human blood. Develop a simple economical assay method suitable for the determination of lycopene from plant and biological sources. Validate the new method according to the International Council for Harmonization (ICH) guidelines for analytical methods.

\subsection{Structure of Lycopene}

Lycopene is a terpene assembled from 8 isoprene units. It is a highly unsaturated straight-chain hydrocarbon with 13 double bonds in which 11 double bonds are conjugated. Eleven conjugated double bonds give lycopene its deep red color. Lycopene is a C40-carotenoid that is made up of eight isoprene units making it a symmetrical tetraterpene. Naturally occurring lycopene is a trans -lycopene as shown in figure 1.

\subsection{Physical and Chemical Properties of Lycopene}

\subsubsection{Physical State}

Lycopene crystals are long red needles. The powder of lycopene is a dark reddish brown.

\subsubsection{Stability}

Lycopene is sensitive to light, oxygen, high temperature, acids, catalyst and metal ions. Lycopene absorbs all but the longest wavelengths of visible light, so it appears red. Other physical properties are shown in the table 1 .

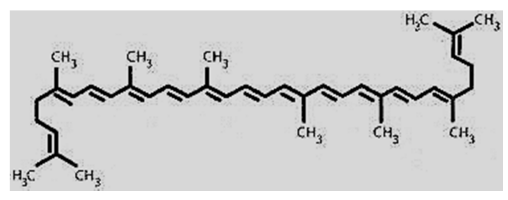

Figure 1. Skeletal formula of all-trans lycopene.

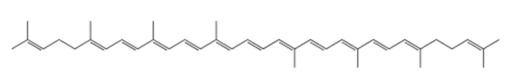

Figure 2. Ball-and-stick model of all-trans lycopene.
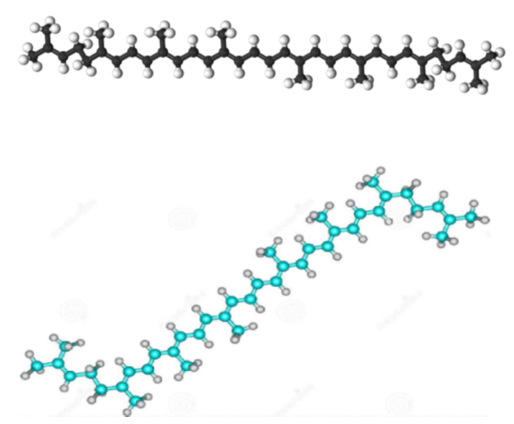

Figure 3. Lycopene structure.

Table 1. Physical properties of Lycopene.

\begin{tabular}{ll}
\hline Chemical formula & $\mathbf{C}_{\mathbf{4 0}} \mathbf{H}_{56}$ \\
\hline Molar mass & $536.89 \mathrm{~g} \cdot / \mathrm{mol}$ \\
Appearance & Deep red solid \\
Density & $0.889 \mathrm{~g} / \mathrm{cm}^{3}$ \\
Melting point & $172-173^{\circ} \mathrm{C}\left(342-343^{\circ} \mathrm{F} ; 445-446 \mathrm{~K}\right)$ \\
Boiling point & $660.9^{\circ} \mathrm{C}$ at $760 \mathrm{mmHg}$ \\
Flash point & $350.7^{\circ} \mathrm{C}\left(663.3^{\circ} \mathrm{F} ; 623.8 \mathrm{~K}\right)$ \\
Solubility in water & Insoluble in Water, methanol and ethanol. \\
Solubility in hexane & $1.0 \mathrm{~g} / \mathrm{L}\left(14^{\circ} \mathrm{C}\right)$ \\
Vapor pressure & $1.33 \cdot 10-16 \mathrm{mmHg}\left(25^{\circ} \mathrm{C}\right)$ \\
Main hazards & Combustible \\
Solubility in organic & Soluble in chloroform, Hexane, Benzene, \\
Solvent & Acetone, Petroleum, ether, Tetrahydrofuran, \\
Refractive index & carbon disulphide and oil. \\
\hline
\end{tabular}

\subsection{Sources of Lycopene}

Fruits and vegetables are the main sources of lycopene. Among them some are high in lycopene include autumn olive, tomatoes, watermelon, pink grapefruit, pink guava, papaya, sea buckthorn, wolfberry (goji, a berry relative of tomato) as shown in figure 4.

Lycopene is also produced by some photosynthetic 
microorganisms like algae, some types of fungus and some bacteria. Watermelon is one of the few foods rich in lycopene. Consumption of watermelon juice increases plasma concentrations of lycopene and $\beta$-carotene in humans.

\subsection{Role of Lycopene in Human Health}

Human intervention, epidemiological and experimental studies have shown strong evidence of the role of lycopene to treat many human diseases.

\subsubsection{Cancer}

The studies of tissue culture by using different cell lines give the chief supporting evidence for the role of lycopene in the cure of cancer. In 1995, it was stated that the possibility of prostate cancer was reduced to $35 \%$ by using 10 or more servings of tomato products per week.

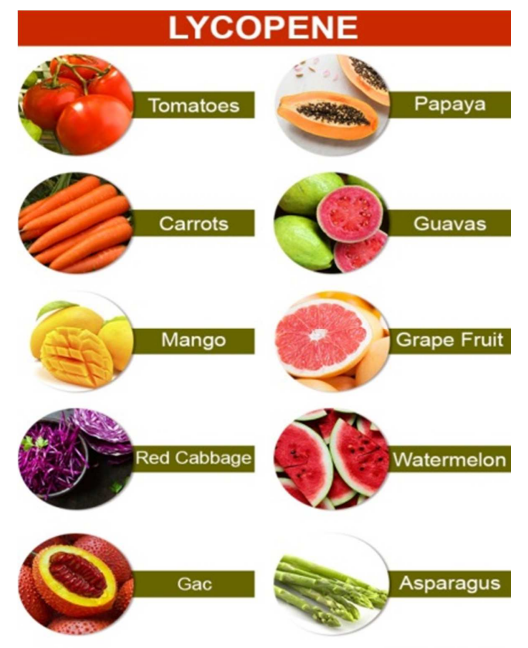

Figure 4. Sources of Lycopene.

In 1997, it was reported by Leveche that the diet of Mediterranean which is rich in tomatoes or tomato containing things was proved to lower cancer. It was shown in some studies that the lycopene level in serum and tissue was to be inversely related to the risk of prostate cancer and breast cancer.

The relationship between serum lycopene and prostatespecific antigen levels was found to be inverse. The study of modern time makes known that the use of $15 \mathrm{mg}$ lycopene per day for three weeks to treat the diagnosed prostate cancer patients before surgery, the results were found that the levels of plasma lycopene were found lower in the comparison to the controls. The volume of tumors in treated patients was found to be smaller. After a three-week dosage to the patients, the surgical treatment of tumors was delayed. The studies of human epidemiological give evidence that the foods which are high in tomatoes may reduce the risk of cervical, colon, esophageal, rectal, and prostate and stomach cancers.

The second most frequently diagnosed cancer worldwide is prostate cancer among men. In Australia, Western Europe, and Northern America the incidence rates are highest, whereas in south-central Asia the incidence rate is lowest in 2008 it was reported that the sixth leading cause of death from cancer among men worldwide was due to prostate cancer. There are many molecular mechanism activities are known for lycopene as an anticancer. Antioxidants are responsible to produce enzymes to save from free radicals, to remove unhealthy abnormal cells on the basis of these results, it is proposed that lycopene has useful effects to eradicate cancers.

\subsubsection{Cardiovascular Disease}

The oxidized low-density lipo-protein which flows in the blood is said to play a vital part in the parthenogenesis of cardiovascular disease (CVD). There are many studies of epidemiological and forthcoming studies all have shown their usage of antioxidant vitamins like vitamin-E and $\beta$-carotene may lessen the menace of cardiovascular disease. There are only a few such studies that have been done with lycopene. The observations which are achieved from epidemiological studies give mostly evidence to support the role of lycopene in the stoppage of cardiovascular disease. The high consumptions of tomato and tomato foodstuffs in the areas of

the Mediterranean have the lowest rate of CVD. According to many studies the association between blood lycopene levels and the hazard of cardiovascular diseases in the opposite. The multicenter case-control study provides the most population -Based indication to assess the role of lycopene in cardiovascular disease. The relationship between adipose tissue antioxidant grade and serious myocardial infarction. In order to raise the stages of $\alpha$ and $\beta$-carotenes, lycopene, and $\alpha$-tocopherol in adipose tissue, the needle aspiration biopsy samples were taken soon after infarction. After the regulation of other variables, it was found that only lycopene and not the other antioxidants to be defensive contrary to cardiovascular disease.

The information which was collected from the more comprehensive analysis in the MALAGA REGION presented the substantial antithetical relationship between the danger of myocardial infarction and lycopene stages in adipose tissue. In literature, the relationship between lycopene intake and the risk of cardiovascular disease has been mentioned from studies of some human dietary intervention. Clinical trials. It was observed that the plasma LDL cholesterol levels were reduced to $14 \%$ when $60 \mathrm{mg}$ per day of lycopene was consumed by 6 healthy human subjects for a period of three months.

According to the study of randomized, cross-over dietary intervention, the usage of 20-150 mg lycopene per day from tomato, tomato juice tomato souse and lycopene capsules for a period of one week, then it was observed that lower levels of protein, lipid and DNA oxidation along with a significant increase in serum lycopene levels.

\subsubsection{Osteoporosis}

From the evidence it is suggested that the oxidative stress is associated with the parthenogenesis of osteoporosis. Oxidative stress caused by reactive species. It is suggested from epidemiological evidence that, certain antioxidants, including vitamin $\mathrm{C}, \mathrm{E}$, and $\beta$-carotene may reduce the risk of osteoporosis. The testified studies which appraise the role of 
lycopene in osteoporosis are a shortage in literature. The effect of lycopene on bone-resorbing osteoclasts were examined by two in vitro tissue culture studies. It was reported that lycopene repressed osteoclastic mineral resorption, development of tartarat resistant phosphatase positive multinucleated osteoclasts, and the making of ROS by osteoclasts. It was made known by two reported studies that the effect of lycopene in the bone-forming osteoblasts. It was shown that the propagation of the osteoblasts is stimulated by lycopene. It is the first report of results about the effect of lycopene on human osteoblasts. In order to study the role of lycopene in postmenopausal women who are at the threat of osteoporosis, a clinical study is being presently carried out. The determination of this study is to measure the position of antioxidants and biomarkers of oxidative stress in postmenopausal women. The study of dietetic mediation will be then undertaken to estimate the role of lycopene in enlightening bone-health and formulating guidelines for the eating of lycopene. Although there is epidemiological evidence in order to understand the valuable properties of tomato. Tomatoes are the biggest source of lycopene.

\subsubsection{Hypertension}

In modern research when the grade one hypertensive patients treated by lycopene supplements for a period of eight weeks then it was found that the reduction of up to $10 \mathrm{mmHg}$ in the systolic blood pressure. The signification of this considered observation in the management of diet for hypertension in the form of concentration of consumed lycopene in relation of a short period of treatment.

\subsubsection{Male Infertility}

It has been considered that oxidative stress is an important factor that contributes to male infertility. When semen of infertile men was tested then it is found that ROS levels of up to $25 \%$. The role of antioxidant vitamins such as vitamin $\mathrm{C}$ and $\mathrm{E}$ in male infertility have been evaluated by some studies, From above-mentioned studies, it is suggested that there is a big role of antioxidants therapy for the treatment male- infertility The studies which provide evidence for the of lycopene in male infertility are very small in numbers. According to one study, it was found that the lycopene levels were in the semen of men with antibody-mediated infertility than fertile controls.

The daily consumption of $8 \mathrm{mg}$ of lycopene in capsule form by 39 infertile males in volunteers between the ages of $21-50$ years, showed that after 12 months the result was that the treatment of lycopene resulted in a significant increase in serum lycopene concentration, sperm motility index, sperm motility, sperm morphology, and functional sperm concentration. The successful pregnant ratio was 18 partners out of 50 subjects, it was the success rate of $36 \%$. There is progress in other studies and there will be a further advancement in the knowledge of the role of lycopene in the treatment of males infertility.

\subsubsection{Neurodegenerative Disease}

The consumption of Oxygen, quantity buys brain is large in relation to its small weight which contributes further to the formation of ROS. The role of antioxidant vitamins and antioxidant phytonutrients has been studied to treat various neurodegenerative disorders. According to few reported studies from the literature, it is shown that there is a lycopene level in patients with Parkinson's disease microangiopathy and vascular elementia. It was reported from one study that there is a direct relationship between high blood lycopene levels and a positive influence on the functional capacity.

\section{Materials and Methods}

\subsection{Materials}

\subsubsection{Chemicals}

Chloroform (AR grade) Methanol (HPLC grade) n-Hexane (AR grade) Ether (AR grade), Acetonitrile (AR Grade) and distilled water.

\subsubsection{Apparatus}

Separating funnel $(1000 \mathrm{ml})$, Beaker $(1000 \mathrm{ml})$, Beaker $(500 \mathrm{ml})$, Beaker $(250 \mathrm{ml})$, Beaker $(100 \mathrm{ml})$, Funnel, Glass rode, Petri dish, Glass vials $(5 \mathrm{ml})$, Tripod stand, Filtration assembly, Measuring cylinder $(500 \mathrm{ml}, 100 \mathrm{ml}, 50 \mathrm{ml})$, Toiser, Pipette $(25 \mathrm{ml})$, Volumetric flask $(2000 \mathrm{ml}, 1000 \mathrm{ml}, 500 \mathrm{ml}$, $250 \mathrm{ml}, 50 \mathrm{ml}, 25 \mathrm{ml}$ ), Test tubes, Test tube stand, Micropipette, Spatula, Reagent bottle and plastic syringe.

\subsubsection{Equipment}

Rotatory evaporator (Butchi), Electricoven (Germany), Incubator (Germany) UV-Vis Spectrophotometer (UV-vis1800, Shimadzu, Japan), HPLC (LC -10 AS Shimadzu, Japan), Ice drier (China) and (FTIR- Carry 600, Agilent).

\subsection{Methods}

\subsubsection{Extraction of Lycopene from Tomato}

Two kilograms of tomato washed with water and then cut by a knife to convert into small pieces. The small pieces of tomato were blended into a blender to form a juice like material.

The blended material was taken quickly into two 2.5-liter bottles in order to protect it from aerial oxidation and light effect. Then by using a beaker of $250 \mathrm{ml}$ the tomato juice poured into a separating funnel. The chloroform of $200 \mathrm{ml}$ added into the separating funnel having tomato juice. On the addition of chloroform solvent, the chloroform sedimented below red material. So, the whole mixture divided into two layers.

After 24 hours three prominent layers formed. These layers are the upper layer is of water, below the water layer a thick yellow-colored layer formed. The red colored chloroform layer sedimented. The chloroform layer sediment because chloroform has a high density as compared to water. The upper water layer poured into a beaker from the mouth of the flask. The chloroform layer released from separating funnel and collected in a volumetric flask by passing through the common filter paper to remove the insoluble matter. The yellow-colored residue obtained in separating funnel. The yellow color of the residue represents that all the red-colored lycopene extracted by chloroform solvent and dried. 


\subsubsection{Extraction of Lycopene from Watermelon}

One kilogram of watermelon red pulp cut by a knife to convert into small pieces. After removing seeds from watermelon pieces, the small pieces were blended into a blender to form a juice like material. The blended material was taken quickly into a one-liter bottle in order to protect it from aerial oxidation and light effect.

Then by using a beaker of $250 \mathrm{ml}$ the watermelon juice poured into a separating funnel of $500 \mathrm{ml}$. Taken five separating funnels of $500 \mathrm{ml}$, in each separating funnel added $200 \mathrm{ml}$ of watermelon juice. The chloroform of $200 \mathrm{ml}$ added in each separating funnel having watermelon juice. On the addition of chloroform solvent, the chloroform sedimented below red material. So, the whole mixture divided into two layers, and lycopene separated and dried.

\subsubsection{Chromatographic Conditions}

Column: C18 (250mmx4.6mm, $5 \mu \mathrm{m})$

Flow rate: $0.7 \mathrm{ml} / \mathrm{min}$.

Injection volume: $20 \mu 1$

Detection: $484 \mathrm{~nm}$

Mobile phase: Methanol: Acetonitrile: Water (65:20:15)

HPLC system: Isocratic

\section{Results and Discussion}

\subsection{Identification of Lycopene by UV-Vis Spectroscopic}

The identification of Lycopene in tomato samples, watermelon samples, and reference samples was confirmed by UV-vis spectroscopic study that all the three samples showed maximum absorption at $484 \mathrm{~nm}$ that was completely matched with the reported standard value. In all the three samples two other compounds showed the same absorption at the same wavelength. All samples of the three obeyed beer lambert's Law.

\subsection{Quantification of Lycopene by UV-vis Spectroscopy}

The quantity of Lycopene by UV-vis spectroscopy from watermelon and tomato at maximum absorption at $484 \mathrm{~nm}$ by using a molar extinction coefficient of $152989 \mathrm{~L} / \mathrm{M}-\mathrm{cm}$ was determined. It was found $40.85 \mathrm{mg} / \mathrm{Kg}$ in extract of tomato and $31.67 \mathrm{mg} / \mathrm{Kg}$ in the extract of watermelon.

The quantity of crude Lycopene from Tomato and watermelon was found by simple measurements. From tomato the crude Lycopene was found $5.49 \mathrm{~g}$ in two $\mathrm{Kg}$ of raw tomato. Similarly, the crude Lycopene from watermelon was found $1.78 \mathrm{~g}$ in one $\mathrm{Kg}$ of raw watermelon.

\subsection{Identification of Lycopene in Tomato and Watermelon by HPLC Method}

For HPLC Identification it was found that the retention times for the reference samples, tomato sample, and watermelon sample were the same. All the three samples were tested by using the same HPLC system under the same conditions of mobile phase (Methanol: 65\%, Acetonitrile: $20 \%$, Water: $15 \%$ ) on the same day. The retention time of lycopene is around 5.0 shown in figure 5 .

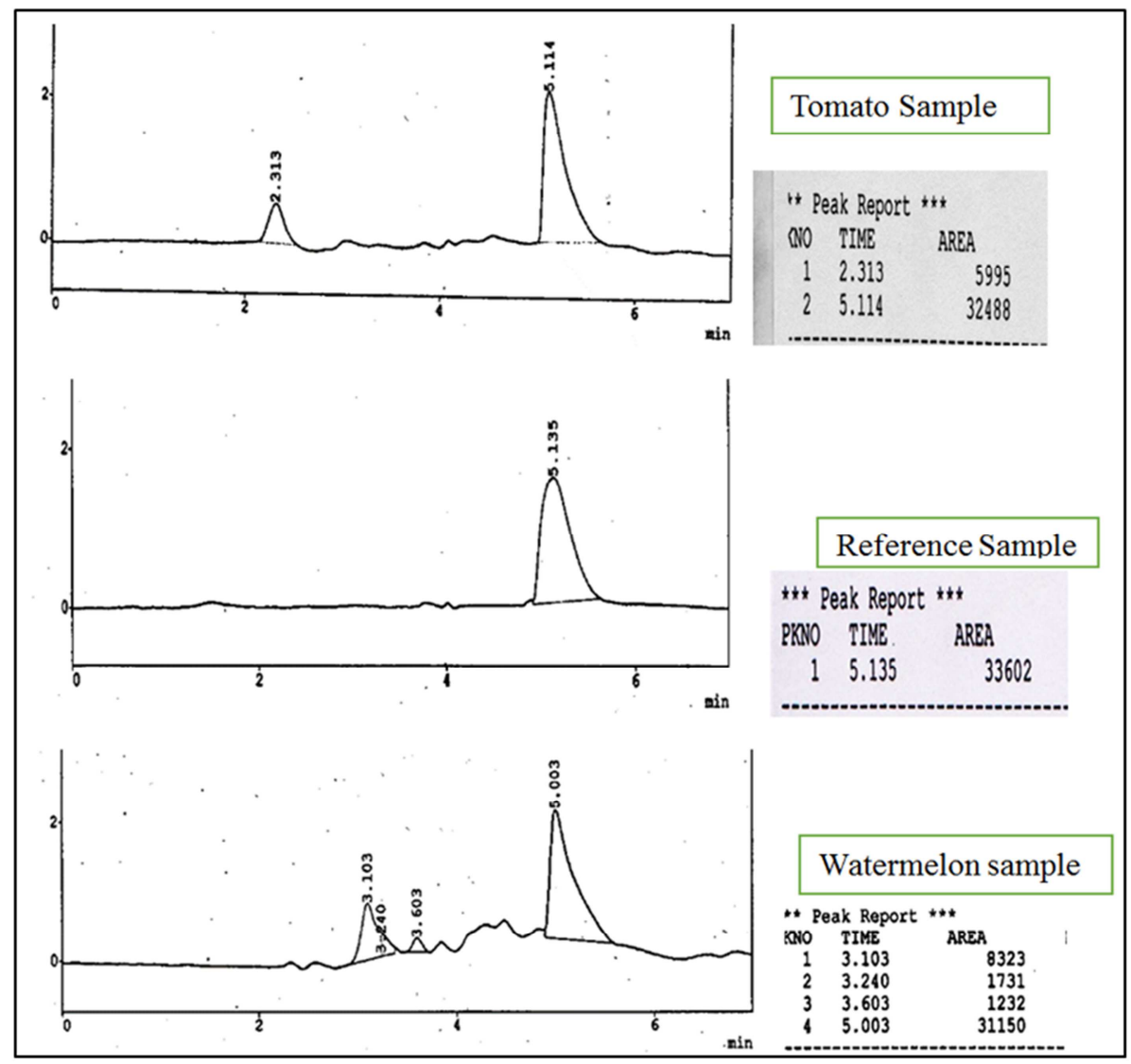




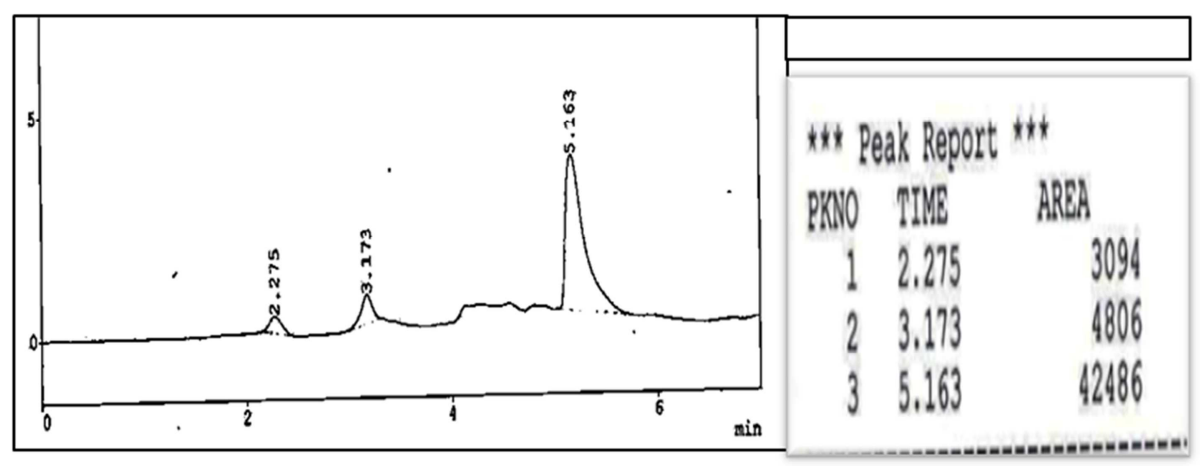

Figure 5. HPLC Identification of Lycopene in Tomato and Watermelon.

\subsection{Validation Parameters Results}

The developed method was validated as per $\mathrm{ICH}$ parameters. The percentage assay was found to be $102 \%$. The linearity of the method was found to be in the range of 0 to $1 \mathrm{mg} / \mathrm{L}$. The correlation coefficient was found to be 0.9994 with a slope of 5416.6. LOD was found to be $0.265 \mathrm{mg} / \mathrm{L}$. LOQ was found to be $0.88 \mathrm{mg} / \mathrm{L}$. The precision of the HPLC method was carried out by injecting a replicate of six concentration of $6.0 \mathrm{mg} / \mathrm{L}$. The $\% \mathrm{RSD}$ for precision was found to be 4.8 for intra-day and 4.7 for inter-day. High percentage recovery showed that the method was free from interferences of the excipients used in the formulations. Ruggedness test results were found with \%RSD 1.6. Robustness test results were found to be with \% RSD 5.5.

The summary of validation parameters the results of the HPLC method are shown in table 2.

Table 2. Results of validation parameters of developed HPLC method.

\begin{tabular}{lll}
\hline Sr No & Parameters & Values found \\
\hline 1 & Linearity and Range & $0-----0.45 \mathrm{mg} / \mathrm{L}$ \\
2 & Correlation coefficient & $0.155----0.3 \mathrm{mg} / \mathrm{L}$ \\
3 & Accuracy (\%recovery) & 0.9994 with Slope 5416.6 \\
4 & Precision (\%RSD) & $102 \%$ \\
$4 \mathrm{a}$ & Intraday & \\
$4 \mathrm{~b}$ & Interlay & 4.8 \\
5 & Ruggedness (\%RSD) & 4.7 \\
6 & Robustness $(\% \mathrm{RSD})$ & 1.6 \\
7 & LOD (mg/L) & 5.5 \\
8 & LOQ (mg/L) & $0.265 \mathrm{mg} / \mathrm{L}$ \\
\hline
\end{tabular}

Table 3. \%age recovery of lycopene in watermelon sample.

\begin{tabular}{llllllll}
\hline \multicolumn{2}{l}{ Watermelon sample Equation for regression line $\mathbf{y}=\mathbf{5 4 1 6 . 6} \mathbf{x}+\mathbf{( - 1 7 3 . 8 6}$} \\
\hline Sr. No & Conc $(\mathbf{m g} / \mathbf{L})$ & Retention time & Peak area & Average peak area & STDEV & \%RSD & \% Recovery \\
\hline 1 & 8.0 & 5.0 min & 41507 & 42569.6667 & 2777.8744 & 6.5 & 98.60 \\
2 & & 45722 & & & & \\
3 & & 40480 & & & & \\
\hline
\end{tabular}

Table 4. \%age recovery of lycopene in blood sample.

\begin{tabular}{llllllll}
\hline \multicolumn{2}{l}{ Blood sample } & & & & \\
\hline Sr. No & Conc $(\mathbf{m g} / \mathbf{L})$ & Retention time & Peak area & Average peak area & STDEV & \%RSD & \% Recovery \\
\hline 1 & 8.0 & $5.0 \mathrm{~min}$ & 41464 & 41902.66667 & 526.13433 & 1.25 & 97.10 \\
2 & & & 42486 & & & \\
3 & & & 41758 & & & \\
\hline
\end{tabular}

Table 5. \%age recovery of lycopene in Tomato sample.

\begin{tabular}{llllllll}
\hline \multicolumn{2}{l}{ Tomato sample } & & & & \\
\hline Sr. No & Conc $(\mathbf{m g} / \mathbf{L})$ & Retention time & Peak area & Avg peak area & STDEV & \%RSD & \% Recovery \\
\hline 3 & 8 & 5.0 min & 41069 & 43268.333 & 538.108 & 1.24 & 100.57 \\
& & 41830 & & & & \\
& & 42742 & & & & \\
\hline
\end{tabular}




\section{Conclusion}

The proposed study describes a new and simple method for the estimation of Lycopene. This method was developed and validated according to $\mathrm{ICH}$ guidelines. It is found to be simple, accurate, and precise. Therefore, the proposed method was used for the routine analysis of lycopene from watermelon, tomato and human blood. The concentration of lycopene in tomato, watermelon, and blood sample could be satisfactory determined using isocratic RP-HPLC system with a UV-VIS detector.

\section{References}

[1] Rao A. V., Agarwal, S.: Role of antioxidant lycopene in cancer and heart disease. J Am College of Knut, 19 (5): 563$569,2000$.

[2] Agarwal, S., Rao, A. V.: Tomato lycopene and its role in human health and chronic diseases. Cana-dian Medical Association Journal, 739-44, 2000.

[3] Stahl, W., Schwarz, W., Sundquist, A. R., Sies, H.: Cis-trans Isomers of lycopene and b-carotene in human serum and tissues. Arch Biochem Biophys, 294: 173-177, 1992.

[4] Rao, A. V., Agarwal, S.: Effect of diet and smoking on serum lycopene and lipid eroxidation. Nutr Res, 18: 713-721, 1998.

[5] Khachik, F., Carvallo, L., Bernstein, P. S., Muir, G. J., Zhao, D. Y., Katz, N. B.: Chemistry, distribution and metabolism of tomato carotenoids and their impact on human health. Exp Biol Med (Maywood), 227: 845-851, 2002.

[6] Rao, A. V., Agarwal, S.: Role of lycopene as antioxidant carotenoid in the prevention of chronic diseases: A review. Nutr Res 19: 305-323, 1999.

[7] Giovannocci, E., Ascherio, A., Rimm, E. B., Stampfer, M. J., Colditz, G. A., Willet, W. C.: Intake of carotenoids and retinol in relation to risk of prostate cancer. J National Cancer Institute 87: 1767-1776, 1995.

[8] LaVecchia, C.: Mediterranean epidemiological evidence on tomatoes and the prevention of digestivetract cancers. Proc Soc Exp Bio Med, 218: 125-128, 1997.

[9] Dorgan, J. F., Sowell, A., Swanson, C. A., et al.: Relationship of serum carotenoids, retinol, a-tocopherol, and selenium with breast cancer risk: results from a prospective study in Columbia, Missouri (United States). Cancer Causes Control, 9: 89-97, 1998.

[10] Gann, P., Ma, J., Giovannucci, E., Willett, W., Sacks, F. M., Hennekens, C. H.: Lower prostate cancer risk in men with elevated plasma lycopene levels: results of a prospective analysis. Cancer Res, 59: 1225-1230, 1999.

[11] Paran, E., Engelhard, Y.: Effect of Lyc-O-Mato, standardized tomato extract on blood pressure, serum lipoproteins, plasma homocysteine and oxidative stress markers in grade 1 hypertensive patients. Proceedings of the 16th Annual Scientific Meeting of the Society of Hypertension, San Francisco, USA, 2001.
[12] Kim, L., Rao, A. V., LG, R.: Effect of lycopene on Prostate LNCaP Cancer Cells in Culture. Journal of Medicinal Food, 5 (4): 181-187, 2002.

[13] Bowen, P., Chen, L., Stacewicz-Sapuntzakis, M., et al.: Tomato sauce supplementation and prostate cancer: lycopene accumulation and modulation of biomarkers of carcinogenesis. Exp Biol Med (Maywood), 227 (10): 886-893, 2002.

[14] Kucuk, O., Wood, D. P. Jr.: Response of hormone refractory prostate cancer to lycopene. J Urol, 167: 651, 2002.

[15] Parthasarathy, S., Steinberg, D., Witztum, J. L.: The role of oxidized low-density lipoproteins in pathogenesis of atherosclerosis. Ann Rev Med, 43: 219-225, 1992.

[16] Rao, A. V.: Lycopene, tomatoes and the prevention of coronary heart disease. Exp Bio Med, 227: 908-913, 1992.

[17] Rao, V., Heber, D.: Future directions and intake recommendations. Scotland U. K.: Caledonian Sci-ence Press, 2001.

[18] Chambless, L. L., Keil, U., Dobson, A., et al.: Population versus clinical view of case fatality from acute coronary heart disease. Results from the WHO MONICA project. 1985-1990. Circulation, 96: 3849-3859, 1997.

[19] Gianetti, J., Pedrinelli, R., Petrucci, R., et al.: Inverse association between carotid intima-media thickness and the antioxidant lycopene in atherosclerosis. Am Heart J, 143 (3): 467-74, 2002.

[20] Iribarren, C., Folsom, A. R., Jacobs, D. R.: Association of serum vitamin levels, LDL susceptibility to oxidation, and sutoantibodies against MDA-LDL with carotid atherosclerosis. Arterioscler Thromb Vasc Biol, 17: 1171-1177, 1997.

[21] Rissanen, T., Vontilainen, S., Nyyssonen, K., Salonen, R., Salonen, J. T.: Low plasma lycopene concentration is associated with increased intima-media thickness of the carotid artery wall. Arteriocler Thromb Vasc Biol, 20: 2677$2687,2000$.

[22] Kohlmeier, L., Kark, J. D., Gomez-Garcia, E., et al.: Lycopene and myocardial infarction risk in the EURAMIC study. Am J Epidemiol, 146: 618-626, 1997.

[23] Gomez-Aracena, J., Sloots, J., Garcia-Rodriguez, A. et al.: Antioxidants in adipose tissue and myo-cardial infarction in Mediterranean area. The EURAMIC study in Malaga. Nutr Metab Cardiovasc Dis, 7: 376-382, 1997.

[24] Fuhramn, B., Elis, A., Aviram, M.: Hypocholesterolemic effect of lycopene and b-carotene is related to suppression of cholesterol synthesis and augmentation of LDL receptor activity in macrophage. Biochem Biophys Res Commun, 233: 658-662, 1997.

[25] Rao, A. V., Agarwal, S.: Bioavailability and in vivo antioxidant properties of lycopene from tomato products and their possible role in the prevention of cancer. Nutr Canc, 31: 199-203, 1998.

[26] Morton, D. J., Barrett-Connor, E. L., Schneider, D. L.: Vitamin C supplement and bone mineral density in postmenopausal women. J Bon Min Res, 16: 135-140, 2001.

[27] Singh, V. N.: A current perspective on nutrition and exercise. J Nutr, 122: 760-765, 1992. 
[28] Ishimi, Y., Ohmura, M., Wang, X., Yamaguchi, M., Ikegami, S.: Inhibition by carotenoids and retinoic acid of osteoclastlike cell formation induced by bone-resorbing agents in vitro. J Clin Biochem Nutr, 27: 113-122, 1999.

[29] Rao, L. G., Krishnadev, N., Banasikowska, K., Rao, A. V.: Lycopene I - Effect on osteoclasts: Lycopene inhibits basal and parathyroid hormone-stimulated osteoclast formation and mineral resorption medi-ated by reactive oxygen species in rat bone marrow cultures. J Med Food, 6 (2): 69-78, 2003.

[30] Kim, L., Rao, A. V., Rao, L. G.: Lycopene II - Effect on osteoblasts: The caroteroid lycopene stimulates cell proliferation and alkaline phosphatase activity of SaOS-2 cells J Med Food, 6 (2): 79-86, 2003.

[31] Park, C. K., Ishimi, Y., Ohmura, M., Yamaguchi, M., Ikegami, S.: Vitamin A and carotenoids stimulate differentiation of mouse osteoblastic cells. J Nutr Sci Vitaminol, 43: 281-296, 1997.

[32] Iwasaki, A., Gagnon, C.: Formation of reactive oxygen species in spermatozoa of infertile patients. Fertil Steril, 57: 409-416, 1992.

[33] Zini, A., de Lamirande, E., Gagnon, C.: Reactive oxygen species in semen of infertile patients: levels of superoxide dismutase and catalase-like activities in seminal plasma and spermatozoa. Int J Androl, 16: 183-188, 1993.

[34] Geva, E., Bartoov, B., Zabludovsky, N., Lessing, J. B., Lerner-Geva, L., Amit, A.: The effect of antioxi-dant treatment on human spermatozoa and fertilization rate in an in vitro fertilization program. Fertil Steril, 66: 4320-4434, 1996.

[35] Kessopoulou, E., Powers, H. J., Sharma, K. K., et al.: A doubleblind randomized placebo crossover-controlled trial using the antioxidant vitamin $\mathrm{E}$ to treat reactive oxygen species associated male infertility. Fertil Steril, 64: 825-831, 1995.

[36] Suleiman, S. A., Ali, M. E., Zaki, Z. M., el-Malik, E. M., Nasr, M. A.: Lipid peroxidation and human sperm motility: protective role of vitamin E. J Androl, 17: 530-537, 1996.

[37] Palan, P., Naz, R.: Changes in various antioxidant levels in human seminal plasma related to immunofertility. Arch Androl, 36: 139-143, 1996.

[38] Mohanty, N. K., Kumar, R., Gupta, N. P.: Lycopene therapy in the management of idiopathic oligoasthenospermia. Ind $\mathrm{J}$ Urol, 56: 102-103, 2001.
[39] Halliwell, B.: Oxidants and the central nervous system: some fundamental questions. Acta Neurologica Scandinavica, 126: 23-33, 1989.

[40] Rao, A. V., Balachandran, B.: Role of oxidative stress and antioxidants in neurodegenerative diseases. Nutritional Neurosciences, 5 (5): 291-309, 2003.

[41] Schmidt, R., Fazekas, F., Hayn, M., et al.: Risk factors for microangiopathy-related cerebral damage in Aistrian stroke prevention study. J Neurol Sci, 152: 15-21, 1997.

[42] Snowdon, D. A., Gross, M. D., Butler, S. M.: Antioxidants and reduced functional capacity in the elderly: finding from the Nun study. J Gerontology Series A - Biological Sciences and Medical Sciences, 51: M10-M16, 1996.

[43] Ascherio et al 1992 Ascherio, A., Stampfer, M. J., Colditz, G. A., Rimm, E. B., Litin, L. \& Willett, W. C. (1992) Correlations of vitamin $\mathrm{A}$ and $\mathrm{E}$ intakes with the plasma concentrations of carotenoids and tocopherols among American men and women. J. Nutr. 122: 1792-1801.

[44] Block et al 1986 Block, G., Hartman, A. M., Dresser, C. M., Carroll, M. D., Gannon, J. \& Gardner, L. (1986) A data-based approach to diet questionnaire design and testing. Am. J. Epidemiol. 124: 453-469.

[45] Brady et al 1996 Brady, W. E., Mares-Perlman, J. A., Bowen, P. \& Stacewicz-Sapuntzakis, M. (1996) Human serum carotenoid concentrations are related to physiologic and lifestyle factors. J. Nutr. 126: 129-137.

[46] Buiatti et al 1996 Buiatti, E., Munoz, N., Kato, I., Vivas, J., Muggli, R., Plummer, M., Benz, M., Franceschi, S. \& Oliver, W. (1996) Determinants of plasma anti-oxidant vitamin levels in a population at high risk for stomach cancer. Int. J. Cancer. 65: $317-322$.

[47] Campbell et al 1994 Campbell, D. R., Gross, M. D., Martini, M. C., Grandits, G. A., Slavin, J. L. \& Potter, J. D. (1994) Plasma carotenoids as biomarkers of vegetable and fruit intake. Cancer Epidemiol. Biomarkers Prev. 3: 493-500.

[48] National Center for Health Statistics 1996 National Center for Health Statistics (1996) Associations of plasma carotenes. 